\title{
Downscaling of seasonal soil moisture forecasts using satellite data
}

\author{
S. Schneider, A. Jann, and T. Schellander-Gorgas \\ Central Institute for Meteorology and Geodynamics, Vienna, Austria \\ Correspondence to: S. Schneider (stefan.schneider@zamg.ac.at) \\ Received: 15 November 2013 - Published in Hydrol. Earth Syst. Sci. Discuss.: 4 December 2013 \\ Revised: 26 May 2014 - Accepted: 25 June 2014 - Published: 6 August 2014
}

\begin{abstract}
A new approach to downscaling soil moisture forecasts from the seasonal ensemble prediction forecasting system of the ECMWF (European Centre for Medium-Range Weather Forecasts) is presented in this study. Soil moisture forecasts from this system are rarely used nowadays, although they could provide valuable information. Weaknesses of the model soil scheme in forecasting soil water content and the low spatial resolution of the seasonal forecasts are the main reason why soil water information has hardly been used so far. The basic idea to overcome some of these problems is the application of additional information provided by two satellite sensors (ASCAT and Envisat ASAR) to improve the forecast quality, mainly to reduce model bias and increase the spatial resolution. Seasonal forecasts from 2011 and 2012 have been compared to in situ measurement sites in Kenya to test this two-step approach. Results confirm that this downscaling is adding skill to the seasonal forecasts.
\end{abstract}

\section{Introduction}

Proper knowledge of soil water content and distribution is important for many applications in earth system sciences. Soil moisture has a significant impact on near-surface parameters like temperature and humidity, low clouds and precipitation by influencing the exchange of heat and water between the soil and the lower atmosphere (Ferranti and Viterbo, 2006; Dharssi et al., 2011). Evapotranspiration, infiltration and runoff depend on soil wetness, as does the sensible heat flux from the surface and the heat stored in soils. Soils provide nutrients for the biosphere, and soil water is also important in biogeochemical cycles (Zreda et al., 2012).

Unfortunately, soil water content is both difficult to measure and forecast. This is due to the high variability in soil water content both in time and space, even over short dis- tances (Western et al., 1999), which can hardly be captured by point measurements. Nevertheless, ground-based methods can be applied over any depth, calibrated accurately, and logged on any timescale (Western et al., 2002). Many of the globally available ground-based soil moisture measurements are thus collected, harmonized, and made available to users through the ISMN (International Soil Moisture Network: http://ismn.geo.tuwien.ac.at; Dorigo et al., 2013). Remote sensing, on the other hand, provides excellent spatial coverage over large areas and spatial representativeness, but the shallow measurement depth, the confounding influence of vegetation, the indirect nature of the method, and relatively infrequent repeat cycles hamper the use of the data (Western et al., 2002).

Due to the processes described above, the need for proper soil moisture characterization in modelling is well understood. Nevertheless, simplifications in the representation of modelled land-surface processes in numerical models are unavoidable. They lead to systematic errors in the soil moisture field, which is degrading forecast quality (Drusch and Viterbo, 2007). Furthermore, deficiencies in the short-range precipitation forecasts and representations of the seasonal vegetation cycle (Balsamo et al., 2009) are intensifying the forecasting problems. (Seasonal) soil moisture forecasts are thus hardly used nowadays, although it could be valuable information. Especially in hydrological applications, including flood forecasting and drought monitoring, one is interested in the root zone soil moisture at the catchment or finer scales, as its knowledge can improve estimates significantly (Wagner et al., 2007). This in turn is necessary for agricultural and food security issues as well as for disaster management. To improve forecast representativeness and accuracy, a new method to downscale seasonal soil moisture forecasts of the ECMWF ensemble forecasting system, providing highresolution soil water forecasts, is presented in this paper. 
Data sources used for the investigation are described in Sect. 2. Section 3 includes the calibration and downscaling approach, and in Sect. 4 the results are presented. Conclusions are drawn in Sect. 5, including an outlook on future work and applications.

\section{Data sources}

Seasonal forecasts as well as reference forecasts of soil moisture are generated at the ECMWF. Soil moisture measurements are available from satellite platforms and in situ measurement sites in the testing region, located in Kenya. In the following subsections, the data sources are described in detail.

\subsection{ASCAT soil moisture data}

The Advanced Scatterometer (ASCAT) is a C-band $(5.255 \mathrm{GHz})$ real-aperture radar operated by EUMETSAT (European Organization for the Exploitation of Meteorological Satellites). It is flown on the METOP satellites. Nearreal-time (about $2 \mathrm{~h}$ after sensing) ASCAT surface soil moisture maps on 25 and $50 \mathrm{~km}$ spatial scales have been available operationally since December 2008 (Wagner et al., 2010). ASCAT data used for this study have been provided by Vienna Technical University. The backscattered measurements are used to estimate the surface soil moisture content (Wagner et al., 2013; their Eq. 1), which is a number ranging between 0 (dry limit) and 1 (moist limit), usually expressed in $\%$. To convert it to volumetric soil moisture content (being comparable to ECMWF model output), the soil porosity is necessary (Wagner et al., 2013; their Eq. 2). There are no reliable porosity data for the target region in Kenya, so this conversion is not possible without introducing an additional error source; model output and COSMOS (COsmicray Soil Moisture Observing System) measurements are thus converted to the index with values between 0 and $100 \%$ to make all data sets comparable. ASCAT data are stored as time series for single grid points, so they were interpolated to the ECMWF model grid $\left(0.7^{\circ}\right.$ resolution $)$ to be comparable. To do this, an inverse distance weighting approach (Shepard, 1968) was used. ASCAT soil moisture is valid for surface soil layers with approximate depths of 1-2 cm. Quality flags for wetlands, snow cover, frozen soil and topographic complexity (Scipal, 2005) have been considered. For the ASCAT grid points investigated over the target region, none of the flags had values which would have made it necessary to reject measurements.

\subsection{Seasonal forecast data from ECMWF}

Seasonal forecasts used for this comparison are produced by the seasonal ensemble prediction system (EPS) of ECMWF. System 4 (Molteni et al., 2011), which was used in this study, has been in operational use since 2011. For the at- mospheric part of the forecasting system, the ECMWF Integrated Forecasting System (IFS) is used, with a horizontal resolution of about $0.7^{\circ}$, and 91 vertical levels with a model top at $\sim 0.01 \mathrm{hPa}$. Soil processes are modelled by H-TESSEL (Hydrology-Tiled ECMWF Scheme for Surface Exchanges over Land; Balsamo et al., 2009, 2011). Data output for soil moisture is provided daily for four vertical soil levels: $0-7,7-28,28-100$, and $100-289 \mathrm{~cm}$. The seasonal forecasts include 51 ensemble members. Forecast runs are started at 00:00 UTC on the 1st of each calendar month, with a lead time of 215 days $(5160 \mathrm{~h})$. Data have been extracted from the Meteorological Archival and Retrieval System (ECMWF, 2013a) for $4 \times 4$ grid points in Kenya.

In order to compare ECMWF output and ASCAT data, the ECMWF data unit has to be transformed from the original volumetric soil water $\left(\mathrm{m}^{3} \mathrm{~m}^{-3}\right)$ to an index with values between 0 and 100 (saturation fraction or soil water index, SWI). H-TESSEL differentiates between six different soil types. Using these soil types, for each of the grid points the SWI in $\%$ has been calculated for the combined 1 st and 2 nd soil layer with

$\mathrm{SWI}=\left(\frac{0.25 \mathrm{SWL}_{1}+0.75 \mathrm{SWL}_{2}}{\mathrm{SWL}_{\mathrm{SAT}}}\right) \cdot 100$,

where $\mathrm{SWL}_{\mathrm{SAT}}\left(\mathrm{m}^{3} \mathrm{~m}^{-3}\right)$ is the saturation value for the grid point (depending solely on the soil type); $\mathrm{SWL}_{i}\left(\mathrm{~m}^{3} \mathrm{~m}^{-3}\right)$ is the forecasted volumetric soil water of the $i$ th layer at the grid point.

\subsection{Reference forecasts from ECMWF}

The reference ensemble is created out of historical IFS analyses of the operational high-resolution forecasting system at ECMWF. This reference is used to find out if the seasonal forecasting system has a prediction skill higher than that of a climatological forecast. Soil moisture data from 00:00 UTC runs for January 2001 to December 2012 from the two upper layers of the H-TESSEL soil scheme have been extracted from the MARS archive to ensure a model climatology with sufficient robustness for comparison. As the resolution of the IFS deterministic run $\left(0.125^{\circ}\right)$ is significantly higher than the seasonal EPS one, the IFS grid points with locations corresponding to the 16 EPS grid points in Kenya have been selected.

The analyses for all the years extracted have been combined, and as a result, a 12-member poor-man ensemble for each of the sixteen model grid points is available as a reference forecast. Equation (1) has been applied to this data set, too.

\subsection{COSMOS station data}

To quantify the forecast quality of the ECMWF seasonal forecasts, two in situ measurement sites in Kenya have been used. They are part of COSMOS. The stationary cosmic-ray 
soil moisture probe measures the neutrons that are generated by cosmic rays within air and soil and other materials, moderated mainly by hydrogen atoms located primarily in soil water. The neutrons are emitted into the atmosphere, where they mix instantaneously on a scale of hundreds of metres. Their density is inversely correlated with soil moisture (Zreda et al., 2012). Figure 1 shows the location of the two probes which are operated by the University of Arizona. Data are freely available on a web page (http://cosmos.hwr.arizona.edu), and have been downloaded for the period 2011-2012. Measurements at the two stations are representative of a soil layer with a vertical extent of 15$30 \mathrm{~cm}$ (depending on the current soil water content), so on average they are representative of the same soil depth as the combined H-TESSEL layer $1(0-7 \mathrm{~cm})$ and layer $2(7-28 \mathrm{~cm})$ data calculated in Eq. (1). The COSMOS stations measure average soil water content within a diameter of a few hectometers (Zreda et al., 2012). The correction to atmospheric water vapour content described by Rosolem et al. (2013) has been applied to the COSMOS level 3 (Zreda et al., 2012) soil moisture data, which are provided in volumetric soil moisture $\left(\mathrm{m}^{3} \mathrm{~m}^{-3}\right)$. Afterwards they were transformed to relative values between 0 and 100 by taking the lowest (highest) value in the measurement time series as $0(100)$ and rescaling all measurements between these two values.

Both COSMOS stations (KLEE: $36.867^{\circ} \mathrm{E} / 0.283^{\circ} \mathrm{N}$; Mpala-North: $36.87^{\circ} \mathrm{E} / 0.486^{\circ} \mathrm{N}$ ) are within the same IFS grid cell $\left(0.7^{\circ}\right.$ resolution of the seasonal EPS $)$, but the nearest grid point which is used for the comparison is different $\left(37.1^{\circ} \mathrm{E} / 0.0^{\circ} \mathrm{N}\right.$ vs. $\left.37.1^{\circ} \mathrm{E} / 0.7^{\circ} \mathrm{N}\right)$. Unfortunately, no other in situ measurement sites are available within eastern Africa, where the satellite downscaling parameters (see Sect. 3) have been available for this investigation.

\section{The calibration and downscaling approach}

To downscale seasonal soil moisture forecasts from the global grid to a $1 \mathrm{~km}$ resolution with satellite data, a twostep approach is necessary. In a first step, the forecast climatology is calibrated, meaning that it has to be shifted to the ASCAT climatology. This is done with a CDF-matching approach (Reichle and Koster, 2004). After this calibration, the relationship between ASCAT and Envisat ASAR (Advanced Synthetic Aperture Radar) can be applied to the seasonal soil moisture forecasts in a second step to gain results on a $1 \mathrm{~km}$ grid.

\subsection{Step 1: calibration with CDF matching}

To match ASCAT and ECMWF cumulative distribution functions, for each global model grid point (within the selected domain), the daily IFS/EPS forecast values of each ensemble member are compared to the available ASCAT measurements. As the forecasting model for each IFS/EPS mem-

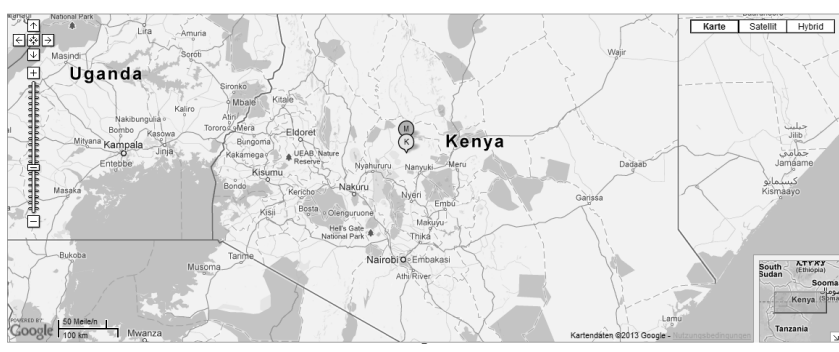

Figure 1. Location of COSMOS in situ soil moisture measurement sites Mpala-North (M) and KLEE (K) (picture from Google Maps).

ber is the same, the number of ASCAT-IFS/EPS data pairs can be increased by the factor of 51, which makes the results more robust from a statistical point of view. Data from seven consecutive seasonal runs (starting dates 1 October 2011 to 1 April 2012) are compared. Based on these data pairs, a polynomial regression analysis is applied to the data set. Polynomials up to the ninth degree have been tested. It was found that beside the linear regression, all polynomials are reasonable for the bias correction. Comparing the mean of ASCAT to the means of IFS/EPS before and after the CDF matching, fourth-order polynomials for the correction turned out to be the most proper ones (i.e. the corrected IFS/EPS mean fits best to the ASCAT mean), followed by eighth- and third-order polynomials. It was thus decided to use fourthorder polynomials, as they take into account the most relevant statistical moments of expectation, variance, skewness and kurtosis. The CDF matching has been applied both to seasonal (EPS) and reference (IFS) forecasts.

\subsection{Step 2: applying the ASCAT-Envisat ASAR relation}

For the disaggregation of coarse-scale microwave measurements, finer resolution satellite data acquired e.g. by synthetic-aperture radars (Das et al., 2011) are applied (Wagner et al., 2013). For $25 \mathrm{~km}$ ASCAT soil moisture data, ASAR data acquired by the Envisat satellite are used. The method exploits the fact that the temporal dynamics of the soil moisture field is often very similar across a wide range of scales, as these are often influenced by the same parameters (e.g. precipitation). This phenomenon is usually referred to as "temporal stability" (Vachaud et al., 1985), meaning that the relationship between local-scale and regional-scale measurements may be approximated by a linear model. To estimate soil moisture on a $1 \mathrm{~km}$ scale from the $25 \mathrm{~km}$ ASCAT soil moisture data,

$m_{\mathrm{S}}^{1 \mathrm{~km}}(t, x, y)=c_{\mathrm{ASAR}}(x, y)+d_{\mathrm{ASAR}}(x, y) m_{\mathrm{S}}^{25 \mathrm{~km}}(t)$

is used (Wagner et al., 2013).

$m_{\mathrm{s}}^{1 \mathrm{~km}}$ is the estimated surface soil moisture content over the $1 \mathrm{~km}$ area centered at the coordinates $(x, y) \cdot m_{\mathrm{s}}^{25 \mathrm{~km}}$ is the calibrated ECMWF soil moisture at forecasting time $t$. 
Originally, $m_{\mathrm{S}}^{25 \mathrm{~km}}$ is the ASCAT soil moisture retrieval at time $t$, but due to the calibration in step 1, this replacement with ECMWF model forecast data can be justified. The coefficients $c_{\mathrm{ASAR}}$ and $d_{\mathrm{ASAR}}$ are the two scaling parameters which are derived from long ASAR backscatter time series using the methods described in Wagner et al. (2008). So far, the coefficients have been available solely for Europe and Australia. For the investigation described herein, they have been calculated for eastern Africa, too.

Tests with the disaggregated ASCAT-ASAR product show that it compares equally well to in situ measurements as the $25 \mathrm{~km}$ ASCAT product (Albergel et al., 2010), but overall the added value of this product is not yet very clear, given that the downscaling parameters are static; i.e., all information about the temporal behaviour still comes from the original $25 \mathrm{~km}$ ASCAT soil moisture product (Matgen et al., 2012). Nevertheless, the product facilitates data handling and interpretation of the soil moisture information on much finer scales (through its advisory flags), making it thus a valuable product from a practical point of view (Wagner et al., 2013). This is likewise true for the ECMWF-ASAR product which is shown in the following section. Comparing the measurements at station KLEE (36.7 on average) to the closest ASCAT grid point (50.8) and the downscaled ASCAT soil moisture data at the four $1 \mathrm{~km}$ grid points surrounding the in situ station $(50.3,50.7,50.0,51.6)$ shows that the downscaling changes the ASCAT measurements just slightly, improving 3 out of 4 .

\section{Results}

For the verification of the forecast quality, weekly mean values have been calculated both for COSMOS measurements and seasonal soil moisture forecasts. Each ensemble member has been averaged separately. This approach was chosen for two reasons. First, possible outliers and unpredictable scales in space and time are smoothened out due to this procedure. Second, it is mainly the trend which is of interest, while daily values of seasonal forecasts should not be used anyway (Molteni et al., 2011). However, anomalous weather events can also be suppressed with this averaging (ECMWF, 2013b).

To calculate statistical measures, the mean of the weekly values has been used for each of the seven seasonal forecasting runs investigated (October 2011 to April 2012). The root mean squared error (RMSE; Wilks, 2006) and the Pearson coefficient of linear correlation (PCC; Wilks, 2006) have been chosen as statistical indices.

Figure 2 shows the results for the seasonal forecast of February 2012 validated at the KLEE station. The forecasting period is characterized by dry soils at the beginning of the period, followed by the rainy season starting in April. During the wet season, the spread of measurements within a week is clearly higher than during dry periods. In the forecasting
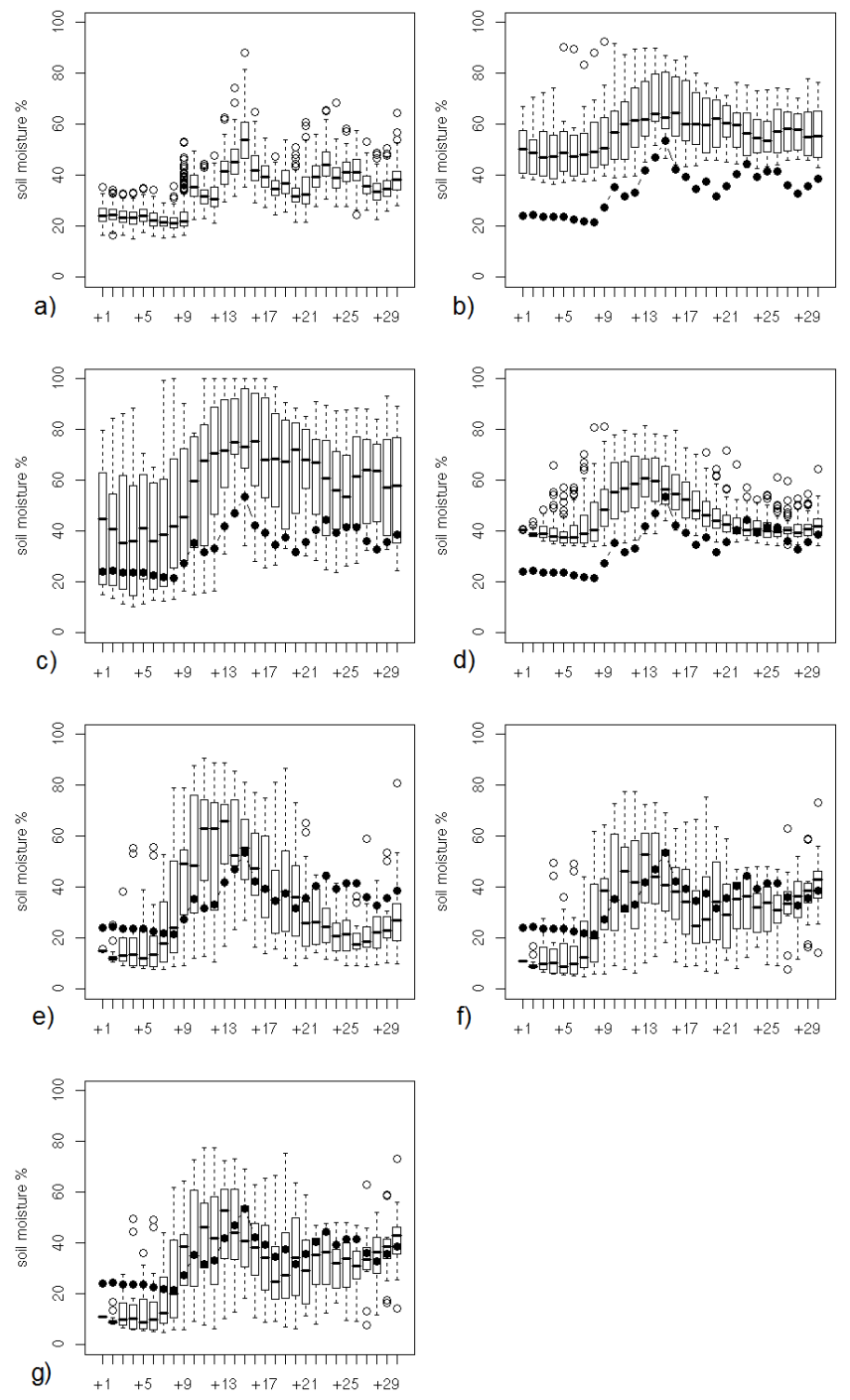

Figure 2. COSMOS soil moisture measurements (a) and forecasts (b-g) for the period February-August 2012 for the KLEE station in Kenya. Numbers on the abscissa indicate the number of weeks since 1 February 2012. For the measurements (a), each boxplot contains 168 values ( 24 hourly values $\times 7$ days). For the forecasts, one column represents all ensemble members, whereas the forecasts of one week (one forecasted value every day) are averaged for each member separately. (b) is the IFS reference climatology, (c) the CDF-matched IFS reference climatology, (d) the CDF-matched and downscaled IFS reference climatology, (e) the EPS ensemble forecast, (f) the CDF-matched EPS ensemble forecast, and (g) the CDFmatched and downscaled EPS ensemble forecast. Black dots in (bg) are the mean values of the COSMOS station for the forecasting period.

plots (Fig. 2b-g), the weekly mean value of the COSMOS station is marked with black dots.

The IFS climatological reference forecast (Fig. 2b) shows the typical behaviour of the model soil, as H-TESSEL is not able to reproduce very dry soils (Balsamo et al., 2009). 
During the dry season, the soil moisture content is thus overestimated in the reference ensemble, and as a consequence, the seasonal cycle is not pronounced enough. This leads to high values in RMSE (24.1), so the climatology is not appropriate for forecast purposes in this case.

Due to the CDF matching (Fig. 2c) and downscaling (Fig. 2d), the tracing of the seasonal cycle can be improved, but soils are still too wet in the model on average. Although the spread is increased mainly due to the CDF matching, moisture is still overestimated by the model for periods with dry soils. Both RMSE and PCC are improved after the downscaling.

The ensemble forecast of 1 February 2012 (Fig. 2e) has the same problem as the reference forecast, with the soil being too wet during the dry season. The seasonal cycle of soil moisture is captured much better in this case, resulting in a low RMSE (12.7), but also a low PCC (0.31). CDF matching to the ASCAT climatology is improving the forecast (Fig. 2f), although soil moisture is even underestimated at the beginning of the forecasting period. Due to this underestimation, RMSE (12.9) is slightly worse compared to the raw EPS forecast, but the seasonal cycle fits the measurements better $(\mathrm{PCC}=0.46)$. Downscaling to $1 \mathrm{~km}$ improves the forecast (Fig. $2 \mathrm{~g}$ ) for this case. The dry soil at the beginning of the forecasting period is still underestimated, but the wet season is predicted much better with the downscaled forecast product. The good forecast quality for months six and seven is still kept after this procedure. Both RMSE (8.1) and PCC (0.73) can be clearly improved compared to the original EPS.

It can thus be summarized for this example that, both for the climatological forecast and the seasonal forecast, the downscaling approach improves the forecast quality.

The averaged results for all seven seasonal forecasts can be seen in Fig. 3. In terms of the grid box size of the seasonal forecasting model, both stations are situated close together. Nevertheless, the forecast quality is slightly different for KLEE and Mpala-North. Concerning the PCC, downscaling is improving the score for Mpala-North, both for climatology and EPS forecasts. For the latter, the improvement (from 0.40 to 0.58 ) is significant. Significance was tested with the Wilcoxon-Mann-Whitney test available in statistical program R. Furthermore, the EPS is better on average than the reference ensemble, but is not significant ( 0.44 vs. 0.40). As shown in Fig. 2 for one case, the seasonal cycle is represented well by the climatology for station KLEE, but with a large wet bias. Due to this, PCC for the climatology is very significantly better at KLEE, as the bias is neglected for computing the correlation. The downscaling is improving PCC compared to the original grid both for climatology and EPS on average, but is not significant.

For the RMSE, the positive impact of the downscaling approach is even clearer. Climatology is hard to beat at Mpala-North, and the original seasonal forecast is significantly worse on average than the reference forecast, but for both systems, the downscaled product is very significantly

\begin{tabular}{|c|c|c|c|c|c|c|c|c|c|c|}
\hline & \multicolumn{5}{|c|}{ KLEE } & \multicolumn{5}{|c|}{ MPALA } \\
\hline & $\begin{array}{l}\text { IFS } \\
\text { CDF }\end{array}$ & $\begin{array}{c}\text { IFS } \\
\text { CDF } 1\end{array}$ & EPS & $\begin{array}{l}\text { EPS } \\
\text { CDF }\end{array}$ & $\begin{array}{l}\text { EPS } \\
\text { CDF } 1\end{array}$ & $\begin{array}{l}\text { IFS } \\
\text { CDF }\end{array}$ & $\begin{array}{c}\text { IFS } \\
\text { CDF } 1\end{array}$ & EPS & $\begin{array}{l}\text { EPS } \\
\text { CDF }\end{array}$ & $\begin{array}{l}\text { EPS } \\
\text { CDF } 1\end{array}$ \\
\hline \multicolumn{11}{|l|}{ RMSE } \\
\hline IFS & $\Delta$ & $\Delta$ & $\Delta$ & $\Delta$ & $\Delta$ & $\Delta$ & $\Delta$ & $\checkmark$ & $\Delta$ & $\uparrow$ \\
\hline IFS CDF & & $\uparrow$ & $\Delta$ & A & $\Delta$ & & $\uparrow$ & $\nabla$ & $\downarrow$ & $\nabla$ \\
\hline IFS CDF 1 & & & $\Delta$ & A & $\Delta$ & & & $\nabla$ & $\downarrow$ & $\nabla$ \\
\hline EPS & & & & $\downarrow$ & $\Delta$ & & & & $\Delta$ & $\Delta$ \\
\hline EPS CDF & & & & & $\Delta$ & & & & & $\nabla$ \\
\hline \multicolumn{11}{|l|}{ PCC } \\
\hline IFS & $\downarrow$ & $\uparrow$ & $\nabla$ & $\nabla$ & $\checkmark$ & $\downarrow$ & $\uparrow$ & 1 & $\uparrow$ & $\uparrow$ \\
\hline IFS CDF & & $\uparrow$ & $\nabla$ & $\boldsymbol{\nabla}$ & $v$ & & $\uparrow$ & $\uparrow$ & A & $\uparrow$ \\
\hline IFS CDF 1 & & & $\nabla$ & $\boldsymbol{\nabla}$ & $\nabla$ & & & $\downarrow$ & $\uparrow$ & $\uparrow$ \\
\hline EPS & & & & $\uparrow$ & $\uparrow$ & & & & $\uparrow$ & 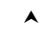 \\
\hline EPS CDF & & & & & $\uparrow$ & & & & & $\uparrow$ \\
\hline
\end{tabular}

Figure 3. Quality of the forecast expressed in RMSE (top block) and PCC (bottom block) for stations KLEE (left) and Mpala-North (right). The arrow in a box points upwards if the forecast (top row) is better than the forecast (left column) on average for the seven forecasting runs. "个" means that the improvement is not significant, “А” significant (75-89.9) and " $\boldsymbol{\Delta}$ " highly significant (90-100). IFS (EPS) is the reference climatology (seasonal forecast), IFS (EPS) $\mathrm{CDF}$ is the bias-corrected one and IFS (EPS) CDF 1 is the biascorrected and downscaled climatology (forecast).

better, reducing the RMSE from 22.9 to 12.7 (for climatology) and from 26.2 to 19.1 (for seasonal EPS). This is also true for KLEE, whereas the EPS outperforms the reference climatology for this station. The RMSE can be very significantly reduced due to the downscaling from 24.5 to 22.2 (for climatology) and from 15.6 to 11.9 (for seasonal EPS).

\section{Conclusions and outlook}

It can be concluded that the proposed downscaling approach with the included calibration is working and is providing useful results. This is demonstrated for two stations in Kenya. The seasonal forecasting system (and also the reference ensemble made up of high-resolution historical forecasts) has known problems in representing dry soils, thus leading to an unrealistic seasonal cycle. Using the information contained in ASCAT soil moisture time series, the described weakness can be partially overcome when calibrating the model forecasts. This CDF matching is working well, even though the soil layers which are compared are of different thicknesses (ASCAT: 1-2 cm, ECMWF: $28 \mathrm{~cm}$ ), and has major advantages over a calibration based on station measurements, as ASCAT satellite soil moisture is available in sufficient quality almost everywhere over land (except in rain forests, deserts and polar regions). Furthermore, this approach is computationally simple. Nevertheless, the polynomials have to be recalculated if changes in the model physics or the 
satellite retrieval algorithm take place. The downscaling to a $1 \mathrm{~km}$ grid with the ASCAT-Envisat ASAR relation is also working well. Statistics show that the downscaling is improving both climatology and seasonal forecasts, whereas results are highly significant for the RMSE. Concerning the forecast quality of the model, it can be stated that the climatology created out of high-resolution analyses is an ambitious benchmark for the seasonal forecast performance.

An application for this approach might be in the early warning of threats to food security in dry regions around the world; this approach has thus been tested in eastern Africa, although the data coverage of in situ measurements is poor in this region. It would be especially interesting to use the downscaled products in combination with crop models. Moreover, it is relevant to monitor soil moisture forecasts to detect weaknesses in forecast quality, as this parameter is still not well captured by weather forecasting models nowadays, although it is a relevant one, especially for convective processes.

In a next step, it is planned to test the approach for other climatic regions and more seasonal forecast runs. Especially for dry climates, it would be interesting to combine the seasonal soil moisture forecasts with drought indices. Furthermore, the variability on the $1 \mathrm{~km}$ grid should be investigated in detail for further improvement of this promising method.

Acknowledgements. We thank Trenton Franz (University of Nebraska Lincoln) and Rafael Rosolem (University of Bristol) for their support in the atmospheric water content correction of the COSMOS data, and two anonymous reviewers for their contributions. The downscaling parameters were derived by the Photogrammetry and Remote Sensing group of the Vienna University of Technology and provided in the frame project Hydrology-SAF, co-funded by EUMETSAT. The work has been partly funded by FFG (Project FarmSupport under the Austrian Space Applications Programme, FFG project number 833421) and ESA (Call AO/1-6889/11/NL/CBi, project GEOSAF).

Edited by: N. Verhoest

\section{References}

Albergel, C., Calvet, J.-C., de Rosnay, P., Balsamo, G., Wagner, W., Hasenauer, S., Naeimi, V., Martin, E., Bazile, E., Bouyssel, F., and Mahfouf, J.-F.: Cross-evaluation of modelled and remotely sensed surface soil moisture with in situ data in southwestern France, Hydrol. Earth Syst. Sci., 14, 2177-2191, doi:10.5194/hess-14-2177-2010, 2010.

Balsamo, G., Viterbo, P., Beljaars, A., van den Hurk, B., Hirschi, M., Betts, A. K., and Scipal, K.: Revised Hydrology for the ECMWF Model: Verification from Field Site to Terrestrial Water Storage and Impact in the Integrated Forecast System, J. Hydrometeorol., 10, 623-643, 2009.
Balsamo, G., Pappenberger, F., Dutra, E., Viterbo, P., and van den Hurk, B.: A revised land hydrology in the ECMWF model: a step towards daily water flux prediction in a fully-closed water cycle, Hydrol. Process., 25, 1046-1054, doi:10.1002/hyp.7808, 2011.

Das, N. N., Entekhabi, D., and Njoku, E. G.: An algorithm for merging SMAP radiometer and radar data for high-resolution soilmoisture retrieval, IEEE T. Geosci. Remote Sensing, 49, 15041512, 2011.

Dharssi, I., Bovis, K. J., Macpherson, B., and Jones, C. P.: Operational assimilation of ASCAT surface soil wetness at the Met Office, Hydrol. Earth Syst. Sci., 15, 2729-2746, doi:10.5194/hess15-2729-2011, 2011.

Dorigo, W. A., Xaver, A., Vreugdenhil, M., Gruber, A., Hegyiová, A., Sanchis-Dufau, A. D., Wagner, W., and Drusch, M.: Global automated quality control of in-situ soil moisture data from the International Soil Moisture Network, Vadose Zone J., 12, doi:10.2136/vzj2012.0097, 2013.

Drusch, M. and Viterbo, P.: Assimilation of screen-level variables in ECMWF Integrated Forecast System: A study on the impact on the forecast quality and analyzed soil moisture, Mon. Weather Rev., 135, 300-314, 2007.

ECMWF: MARS User Guide, ECMWF Technical Notes, January 2013, 55 pp., 2013a.

ECMWF: User Guide to ECMWF forecast products, Version 1.1, July 2013, 129 pp., available at: http://www.ecmwf.int/products/ forecasts/guide/index.html, (last access: 13 November 2013), 2013 b.

Ferranti, L. and Viterbo, P.: The European Summer of 2003: Sensitivity to Soil Water Initial Conditions, J. Climate, 19, 3659-3680, 2006.

Matgen, P., Fenicia, F., Heitz, S., Plaza, D., De Keyser, R., Pauwels, V. R. N., Wagner, W., and Savenije, H.: Can ASCAT-derived soil wetness indices reduce predictive uncertainty in well-gauged areas? A comparison with in situ observed soil moisture in an assimilation application, Adv. Water Resour., 44, 49-65, 2012.

Molteni, F., Stockdale, T., Balmaseda, M., Balsamo, G., Buizza, R., Ferranti, L., Magnusson, L., Mogensen, K., Palmer, T., and Vitard, F.: The new ECMWF seasonal forecasting system (System 4), ECMWF Technical Memorandum, Technical Report No. 656, 49 pp., 2011.

Reichle, R. H. and Koster, R. D.: Bias reduction in short records of satellite soil moisture, Geophys. Res. Lett., 31, L19501, doi:10.1029/2004GL20938, 2004.

Rosolem, R., Shuttleworth, W. J., Zreda, M., Franz, T. E., Zeng, X., and Kurc, S. A.: The effect of atmospheric water vapour on neutron count in the cosmic-ray soil moisture observing system, J. Hydrometeorol., 14, 1659-1671, doi:10.1175/JHM-D-120120.1, 2013.

Scipal, K.: Definition of Quality Flags, ASCAT Soil Moisture Report Series, 7, Institute of Photogrammetry and Remote Sensing, Vienna University of Technology, Austria, 2005.

Shepard, D.: A two-dimensional interpolation function for irregularly spaced data, Proc. 23rd ACM Nat. Conf., Brandon/Systems Press, Princeton, NJ, 517-524, 1968.

Vachaud, G., Passerat de Silans, A., Balabanis, P., and Vauclin, M.: Temporal stability of spatially measured soil water probability density function, Soil Sci. Soc. Am., 49, 822-828, 1985. 
Wagner, W., Blöschl, G., Pampaloni, P., Calvet, J.-C., Bizzarri, B., Wigneron, J.-P., and Kerr, Y.: Operational readiness of microwave remote sensing of soil moisture for hydrologic applications, Nord. Hydrol., 38, 1-20, 2007.

Wagner, W., Pathe, C., Doubkova, M., Sabel, D., Bartsch, A., Hasenauer, S., Blöschl, G., Scipal, K., Martinez-Fernandez, J., and Löw, A.: Temporal stability of soil moisture and radar backscatter observed by the Advanced Synthetic Aperture Radar (ASAR), Sensors, 8, 1174-1197, 2008.

Wagner, W., Bartalis, Z., Naeimi, V., Park, S.-E., Figa-Saldana, J., and Bonekamp, H.: Status of the METOP ASCAT soil moisture product, IEEE International Geoscience and Remote Sensing Symposium 2010 (IGARSS2010), Honolulu, Hawaii, USA, 276-279, 2010.

Wagner, W., Hahn, S., Kidd, R., Melzer, T., Bartalis, Z., Hasenauer, S., Figa, J., de Rosnay, P., Jann, A., Schneider, S., Komma, J., Kubu, G., Brugger, K., Aubrecht, C., Züger, J., Gangkofner, U., Kienberger, S., Brocca, L., Wang, Y., Blöschl, G., Eitzinger, J., Steinnocher, K., Zeil, P., and Rubel, F.: The ASCAT Soil Moisture Product: A Review of its Specifications, Validation Results, and Emerging Applications, Meteorol. Z., 22, 5-33, 2013.
Western, A. W., Grayson, R. B., Blöschl, G., Willgoose, G. R., and McMahon, T. A.: Observed spatial organization of soil moisture and its relation to terrain indices, Water Resour. Res., 35, 797810, doi:10.1029/1998WR900065, 1999.

Western, A. W., Grayson, R. B., and Blöschl, G.: Scaling of soil moisture: a hydrologic perspective. Annu. Rev. Earth Planet. Sci., 30, 149-180, doi:10.1146/annurev.earth.30.091201.140434, 2002.

Wilks, D. S.: Statistical Methods in the Atmospheric Sciences, 2nd Edn., Academic Press, International Geophysics Series, 91, 648 pp., ISBN 13: 978-0-12-751966-1, 2006.

Zreda, M., Shuttleworth, W. J., Zeng, X., Zweck, C., Desilets, D., Franz, T., and Rosolem, R.: COSMOS: the COsmic-ray Soil Moisture Observing System, Hydrol. Earth Syst. Sci., 16, 40794099, doi:10.5194/hess-16-4079-2012, 2012. 